\title{
Synthesis of Carbazoles and Dihydrocarbazoles by a Divergent Cascade Reaction of Donor-Acceptor Cyclopropanes
}

\author{
Matteo Faltracco, Matteo Damian, and Eelco Ruijter*
}

Cite This: Org. Lett. 2021, 23, 7592-7596

Read Online

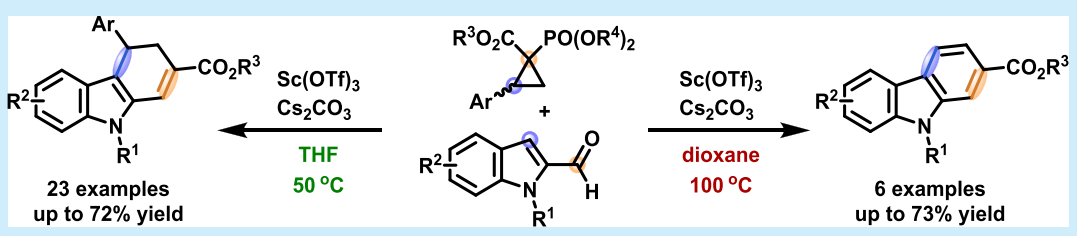

ABSTRACT: An alkylation/olefination cascade of indolecarboxaldehydes and phosphonate-functionalized donor-acceptor cyclopropanes affords functionalized dihydrocarbazoles and cyclohepta[cd]indoles in formal $(3+3)$ and $(4+3)$ cycloadditions. A minor modification to the reaction conditions also allows access to the fully aromatic heterocyclic scaffolds by thermal loss of an electron-rich aryl moiety.

\begin{abstract}
arbazoles and their di- and tetrahydro derivatives have gained considerable interest from the synthetic community owing to their presence in a wide range of natural products and their diverse biological activities. ${ }^{1}$ Consequently, these scaffolds are highly relevant for drug discovery. ${ }^{2}$ Despite the development of diverse synthetic methods for the construction of carbazoles and their dihydro derivatives, ${ }^{3}$ efficient new methods allowing alternative substitution patterns remain urgently required. Therefore, we set out to develop an efficient and versatile approach based on donor-acceptor cyclopropanes (DACs). DACs have emerged as highly valuable building blocks in organic synthesis: ${ }^{4}$ Their high ring strain, combined with a vicinal substitution pattern of donor and acceptor groups, allows the facile generation of a reactive 1,3zwitterion. Although numerous reactions of DACs have been reported over the years, $(3+2)$ cycloadditions ${ }^{5}$ have received considerably more attention compared with their $(3+3)^{6}$ and $(3+4)^{7}$ counterparts. This is due to the high number of $1,2-$ dipolarophiles compared with 1,3- and 1,4- dipolar reaction partners. Owing to their frequent occurrence in natural products, ${ }^{8}$ indole derivatives have been extensively used as 1,2-dipolarophiles in $(3+2)$ cycloadditions. ${ }^{9}$ However, the vast majority of indole-based natural products feature a tetrahydrocarbazole or $\beta$-carboline framework, ${ }^{10}$ accessible only via $(3+3)$ cycloaddition. Unfortunately, given the natural reactivity of indoles as 1,2-dipolarophiles, $(3+3)$ and other types of cycloadditions are considerably more difficult to achieve. To tackle this issue, it is necessary to introduce dedicated functionalities that could divert the usual reaction pathway (Scheme 1B). However, these examples are rare and substrate-limited and require multistep synthesis of the starting materials. $^{11}$
\end{abstract}

Typically, the acceptor moiety of DACs comprises two ester functionalities, which may be replaced with sulfones, ketones,
Scheme 1. (A) $(3+2)$ Cycloaddition of DACs and Indoles, (B) $(3+3)$ Cycloaddition of DACs and Alkenyl/ Alkynylindoles, and (C) $(3+3)$ Cycloaddition of DACs and Indolecarboxaldehydes

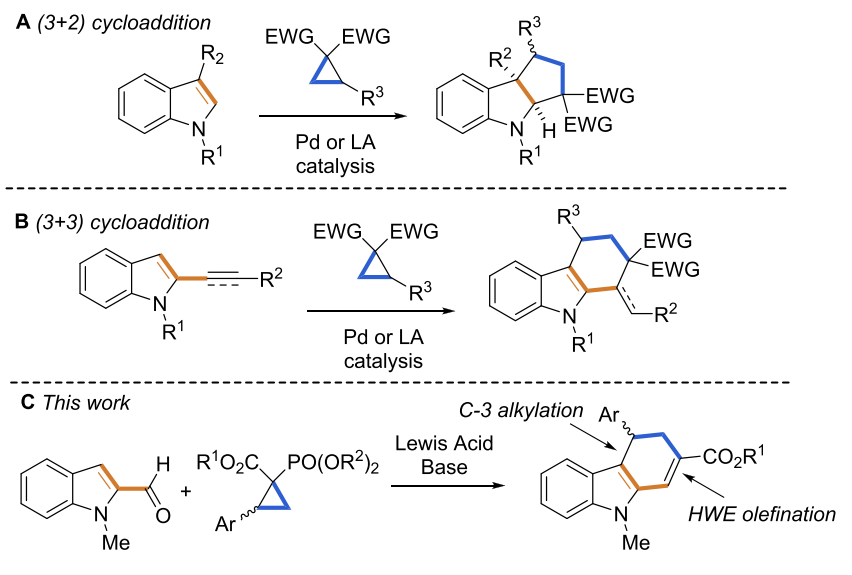

nitriles, or electron-poor arenes. ${ }^{12}$ We recently demonstrated that the previously neglected phosphonates are suitable acceptor moieties, allowing Horner-Wadsworth-Emmons (HWE) olefination with aldehydes upon activation of the DAC. Thus vinylcyclopropanes react with salicylaldehydes

Received: August 20, 2021

Published: September 20, 2021 
Table 1. Reaction Optimization ${ }^{a}$

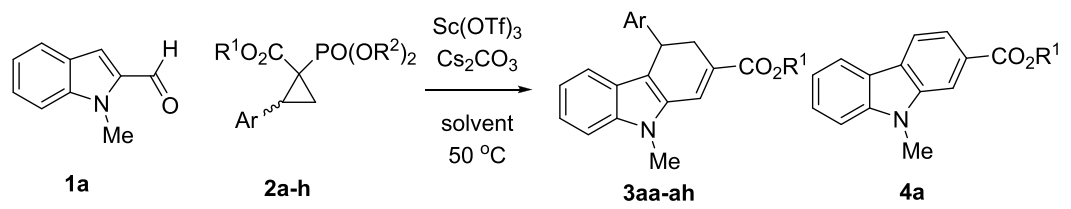

\begin{tabular}{|c|c|c|c|c|c|c|c|}
\hline entry & 2 & $\mathrm{R}^{1}$ & $\mathrm{R}^{2}$ & $\mathrm{Ar}$ & solvent & yield $3(\%)^{b}$ & yield $4(\%)^{b}$ \\
\hline $1^{c}$ & $2 a$ & $\mathrm{Me}$ & $\mathrm{Me}$ & 4-methoxyphenyl & THF & 9 & \\
\hline 2 & $2 a$ & $\mathrm{Me}$ & $\mathrm{Me}$ & 4-methoxyphenyl & THF & 23 & \\
\hline 3 & $2 \mathbf{b}$ & Et & Et & 4-methoxyphenyl & THF & 21 & \\
\hline 4 & $2 c$ & Et & $i \operatorname{Pr}$ & 4-methoxyphenyl & THF & $46^{e}$ & \\
\hline 5 & $2 d$ & $i \operatorname{Pr}$ & $i \operatorname{Pr}$ & 4-methoxyphenyl & THF & 30 & \\
\hline 6 & $2 \mathrm{e}$ & $i \operatorname{Pr}$ & $\mathrm{Me}$ & 4-methoxyphenyl & THF & 26 & \\
\hline 7 & $2 f$ & Et & $i \operatorname{Pr}$ & 4-methylthiophenyl & THF & 32 & \\
\hline 8 & $2 \mathrm{~g}$ & Et & $i \operatorname{Pr}$ & 3,4-methylenedioxyphenyl & THF & 29 & \\
\hline 9 & $2 \mathrm{~h}$ & $i \operatorname{Pr}$ & $i \operatorname{Pr}$ & 2,4,6-trimethoxyphenyl & THF & $68^{d}$ & \\
\hline 10 & $2 \mathrm{~h}$ & $i \operatorname{Pr}$ & $i \operatorname{Pr}$ & 2,4,6-trimethoxyphenyl & 1,4-dioxane & 33 & \\
\hline 11 & $2 \mathrm{~h}$ & $i \operatorname{Pr}$ & $i \operatorname{Pr}$ & 2,4,6-trimethoxyphenyl & 1,4-dioxane $e^{e}$ & 53 & 10 \\
\hline 12 & $2 \mathrm{~h}$ & $i \operatorname{Pr}$ & $i \operatorname{Pr}$ & 2,4,6-trimethoxyphenyl & 1,4-dioxane ${ }^{f}$ & & $73^{d}$ \\
\hline
\end{tabular}

${ }^{a}$ Reaction conditions: $1 \mathrm{a}(0.2 \mathrm{mmol}), \mathbf{2 a}-\mathbf{h}(0.6 \mathrm{mmol}), \mathrm{Sc}(\mathrm{OTf})_{3}(0.6 \mathrm{mmol})$, and $\mathrm{Cs}_{2} \mathrm{CO}_{3}(0.6 \mathrm{mmol})$ in $1 \mathrm{~mL}$ of solvent for $24 \mathrm{~h} .{ }^{b} \mathrm{Determined}$ by ${ }^{1} \mathrm{H}$ NMR with internal standard. ${ }^{c}$ Performed with $2 \mathrm{a}(0.2 \mathrm{mmol}), \mathrm{Sc}(\mathrm{OTf})_{3}(0.2 \mathrm{mmol})$, and $\mathrm{Cs}_{2} \mathrm{CO}_{3}(0.2 \mathrm{mmol})$. ${ }^{d}$ Isolated yields. ${ }^{e}$ Reaction performed at $80^{\circ} \mathrm{C} .{ }^{f}$ Reaction performed at $100^{\circ} \mathrm{C}$.

Scheme 2. Scope of the Reaction toward Dihydrocarbazoles and Cyclohepta $[c d]$ indoles $^{a}$
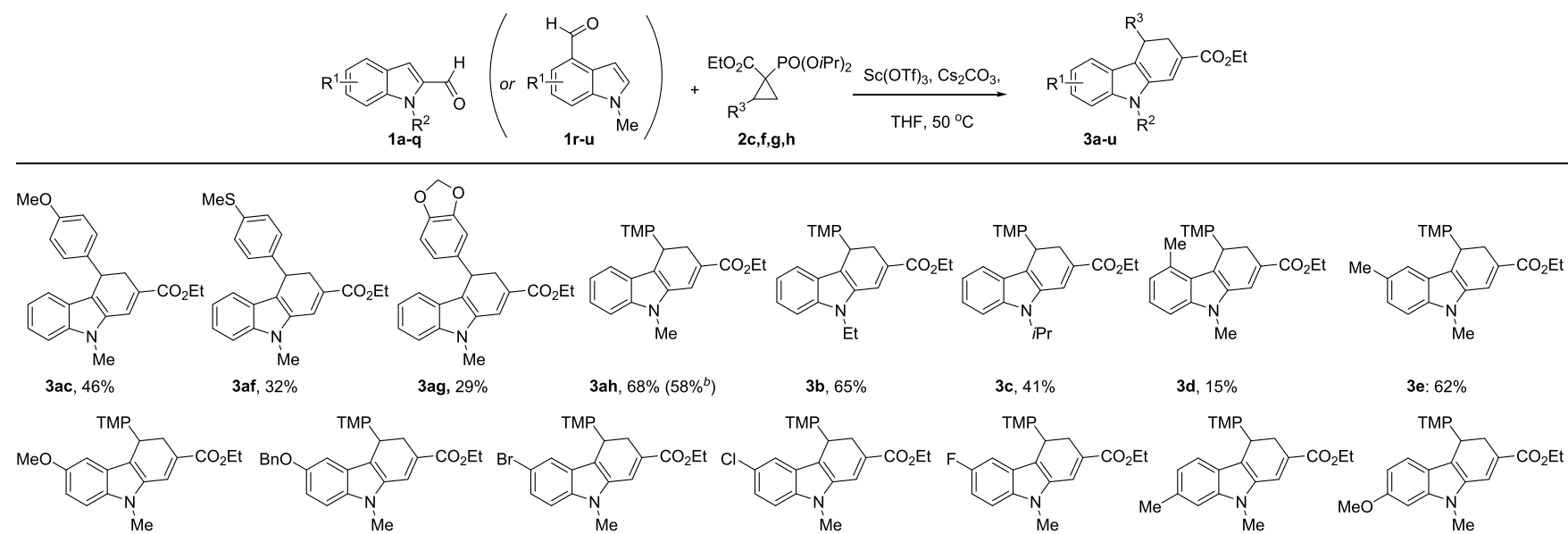

3af, $32 \%$

3ag, $29 \%$
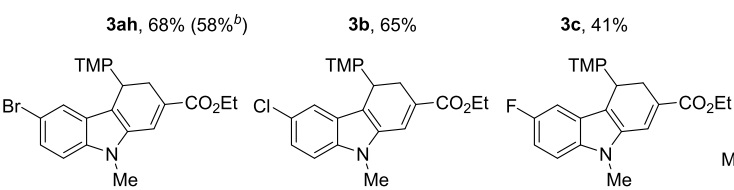

3d, $15 \%$

3e: $62 \%$

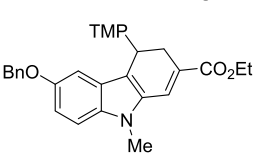

he $67 \%$

$3 \mathbf{3 i}, 69 \%$
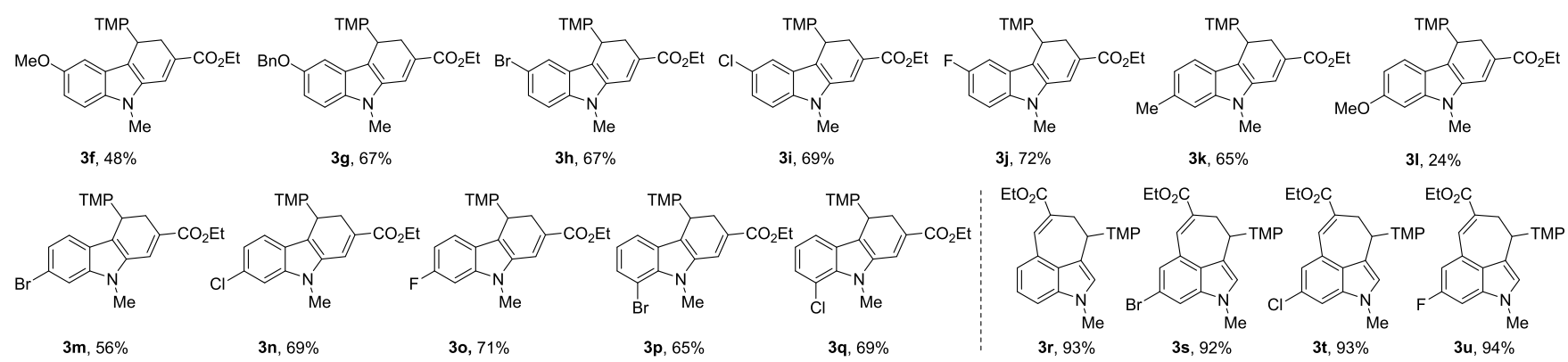

${ }^{a}$ Reaction conditions: $\mathbf{1 a}-\mathbf{u}(0.2 \mathrm{mmol}), \mathbf{2 a}-\mathbf{h}(0.6 \mathrm{mmol}), \mathrm{Sc}(\mathrm{OTf})_{3}(0.6 \mathrm{mmol})$, and $\mathrm{Cs}_{2} \mathrm{CO}_{3}(0.6 \mathrm{mmol})$ in $\mathrm{THF}(1 \mathrm{~mL}), 50{ }^{\circ} \mathrm{C}, 24 \mathrm{~h}$. ${ }^{b}$ Performed on a $1 \mathrm{mmol}$ scale. TMP $=2,4,6$-trimethoxyphenyl.

under palladium catalysis in an olefination/allylation cascade to give benzoxepins in a formal $(4+3)$ cycloaddition. $^{13}$

We realized that this concept could be more generally applicable to aldehydes with a nearby nucleophilic functionality. More specifically, we envisioned that indole-2-carboxaldehydes could react with DACs to give 3,4-dihydrocarbazoles in an all-carbon $(3+3)$ cycloaddition (Scheme 1C). However, when we subjected 1a to cyclization with the previously used vinylcyclopropane under palladium catalysis, ${ }^{13}$ no conversion was observed.

Postulating that a more carbocationic character on the cyclopropane might more effectively promote the attack of the indole C3 position, we switched to arylcyclopropanes in combination with a Lewis acid and a noncoordinating base. Preliminary results proved the feasibility of this reaction, affording the desired dihydrocarbazole $3 a a$, albeit in low yield (Table 1 , entry 1 ).

We then began an extensive investigation of the types and stoichiometries of arylcyclopropanes, bases, and Lewis acids. (For details, see the Supporting Information.) Unfortunately, only scandium(III) triflate was able to promote the reaction and only in stoichiometric amount. We suspect that the dialkylphosphate ion formed during the olefination step may bind to the scandium cation, thereby lowering its Lewis acidity. 
Only minor improvements were observed after a thorough stoichiometry optimization (entry 2). We then focused our attention on the substitution pattern of the cyclopropane. By varying the ester and the phosphonate substituents (entries 3$6)$, we found the best combination to be $2 c\left(R^{1}=E t, R^{2}=i P r\right)$. Finally, comparing different aryl substituents $(\mathbf{2} \mathbf{f}-\mathbf{h}$, entries $7-$ $9)$, we observed the highest conversion with $2 \mathbf{h}\left(\mathrm{R}^{3}=2,4,6\right.$ trimethoxyphenyl). ${ }^{14}$ Having optimized the reactants, we attempted to maximize the conversion to $3 \mathrm{ah}$ by increasing the reaction temperature, using 1,4-dioxane as the solvent instead of THF because of its higher boiling point. To our surprise, when the reaction was performed at $80{ }^{\circ} \mathrm{C}$, we isolated carbazole $4 \mathrm{a}$ in $10 \%$ yield in addition to the desired dihydrocarbazole $3 \mathrm{ah}$. A further increase in the temperature to $100{ }^{\circ} \mathrm{C}$ selectively afforded $4 \mathrm{a}$ in $73 \%$ yield without any traces of $3 \mathrm{ah}$.

With the optimal conditions in hand, we first focused on the scope of the dihydrocarbazole synthesis (Scheme 2). We began by investigating the influence of indole $\mathrm{N} 1$ substituents. Comparing products $3 \mathbf{a h}, \mathbf{3 b}$, and $\mathbf{3 c}$, increasing the steric bulk at the indole $\mathrm{N} 1$ position appears to negatively affect the yield. Steric effects also appear to play a role with C4 substituents, as $3 \mathrm{~d}$ was obtained in only low yield (15\%). In contrast, C5substituted indoles performed well and consistently (always between 60 and $70 \%$ ), regardless of their electronic nature $(\mathbf{3} \mathbf{e}-\mathbf{3 j})$. Surprisingly, the 5 -methoxy-substituted product $3 \mathbf{f}$ was isolated in somewhat lower yield, whereas the analogous benzyloxy-substituted product $3 \mathrm{~g}$ was obtained in $67 \%$ yield. A similar trend was observed for C6 substituents $(3 \mathbf{k}-\mathbf{o})$. Only the 6-methoxy-substituted product 31 showed a lower yield, possibly due to some in situ demethylation caused by the excess of Lewis acid. Moreover, C7 substituents are also well tolerated, affording the desired dihydrocarbazoles in good yields $(3 \mathbf{p}-3 \mathbf{q})$. Finally, we also attempted to achieve a $(4+3)$ cycloaddition by moving the aldehyde to the $\mathrm{C} 4$ position. Delightfully, we observed the formation of the sevenmembered product $3 \mathbf{r}$ in excellent yield (92\%). Similarly good results were obtained for substituted cyclohepta $[c d]$ indoles $3 \mathbf{s}-\mathbf{u}$. This heterocyclic scaffold is present in several alkaloids $^{15}$ and is particularly hard to obtain using cascade reactions. Indeed, we found only one other method using DACs and indoles bearing a strong Michael acceptor at the C4 position. $^{11 \mathrm{e}}$

Intrigued by the formation of carbazole $4 a$, we next investigated the generality of the arene elimination. From the initial reaction optimization, we already established that 4 a could be obtained as the sole product in good yield when dioxane was used as the solvent at $100{ }^{\circ} \mathrm{C}$. Gratifyingly, carbazoles $4 \mathbf{b}, \mathbf{4 e}, \mathbf{4 k}, \mathbf{4 m}$, and $4 \mathrm{q}$ were also obtained in reasonable to good yield using this alternative procedure (Scheme 3). As in the formation of dihydrocarbazoles 3, substituents on the indole ring did not seem to influence the reaction efficiency, regardless of their position or electronic character. Interestingly, the yields observed for carbazoles $\mathbf{4}$ are comparable to those for the corresponding dihydrocarbazoles 3, suggesting that elimination of the trimethoxyphenyl fragment occurs (with high efficiency) after the cyclization. To prove this hypothesis, we heated $3 \mathrm{ah}$ to $100{ }^{\circ} \mathrm{C}$ in dioxane in the absence of $\mathrm{Sc}(\mathrm{OTf})_{3}$ and/or $\mathrm{CsCO}_{3}$. In all cases, carbazole 4a was isolated in quantitative yield, indicating that the aromatization is a purely thermal process. ${ }^{16}$

Interestingly, under the same conditions, we did not observe any trace of $4 \mathbf{t}$ but full conversion to $3 \mathrm{t}$ in comparable yield to
Scheme 3. Scope of the Reaction toward Carbazoles ${ }^{a}$

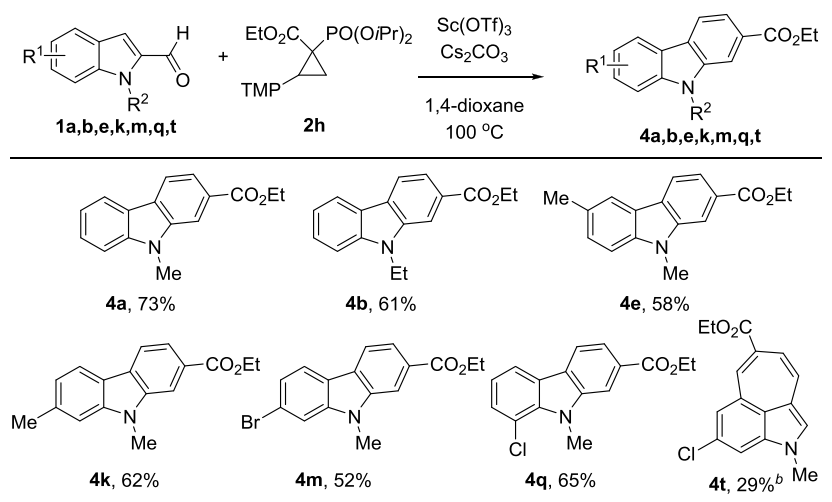

${ }^{a}$ Reaction conditions: 1 (0.2 mmol), $2(0.6 \mathrm{mmol}), \mathrm{Sc}(\mathrm{OTf})_{3}(0.6$ $\mathrm{mmol})$, and $\mathrm{Cs}_{2} \mathrm{CO}_{3}(0.6 \mathrm{mmol})$ in 1,4-dioxane $(1 \mathrm{~mL}), 100{ }^{\circ} \mathrm{C}, 24 \mathrm{~h}$. ${ }^{b}$ Additional $24 \mathrm{~h}$ of reaction time in toluene at $130{ }^{\circ} \mathrm{C}$.

the previous conditions. Apparently, the energetic barrier of the elimination is higher in this case, possibly due to the lower aromaticity of the seven-membered ring. However, upon additional stirring at $130{ }^{\circ} \mathrm{C}$ in toluene for $24 \mathrm{~h}$, we were able to obtain $4 \mathbf{t}$ in modest yield.

To further expand the scope of accessible carbazoles, we sought to develop a rapid and straightforward method to oxidize the corresponding dihydrocarbazoles. Indeed, by treating a representative group of dihydrocarbazoles 3 with 2,3-dichloro-5,6-dicyano-1,4-benzoquinone (DDQ) for only 5 min, we were able to obtain six 4-arylcarbazoles (5) in excellent yield (Scheme 4).

Scheme 4. Oxidation of Dihydrocarbazoles with $\mathrm{DDQ}^{a}$

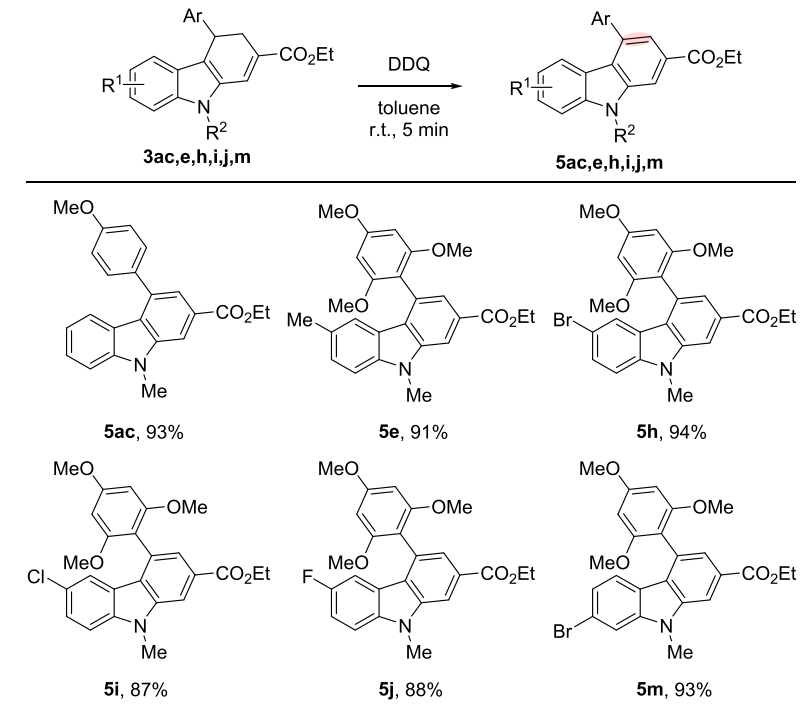

${ }^{a}$ Reaction conditions: $3(0.10 \mathrm{mmol})$, DDQ $(0.11 \mathrm{mmol})$ in toluene $(0.5 \mathrm{~mL}), 0{ }^{\circ} \mathrm{C}, 5 \mathrm{~min}$.

Finally, we focused our attention on the mechanism of the $(3+3)$ cycloaddition, notably on establishing the order of events. We previously observed that $\mathrm{C} 4$ substituents significantly decreased the yield (3d), probably due to steric effects, suggesting that the alkylation step should takes place prior to the HWE olefination, contrary to what we observed with vinylcyclopropanes in palladium-catalyzed $(4+3)$ cycloadditions. ${ }^{13}$ Moreover, because electron density at the 
C3 position is a crucial factor for the cyclization, it is not surprising that indole-4-carboxaldehydes $(3 \mathbf{r}-3 \mathbf{u})$ performed better than indole-2-carboxaldehydes $(3 \mathbf{a h}-\mathbf{3 q})$. Indeed, in the former case, the $\mathrm{C} 3$ position is more electron-rich than that in the latter (due to inductive and resonance effects). To gain further support for the proposed mechanism, we performed the reaction with the $\mathrm{C} 3$ methyl-substituted indolecarboxaldehyde 1v (Scheme 5A). As expected, no reaction was

\section{Scheme 5. Mechanistic Investigation}

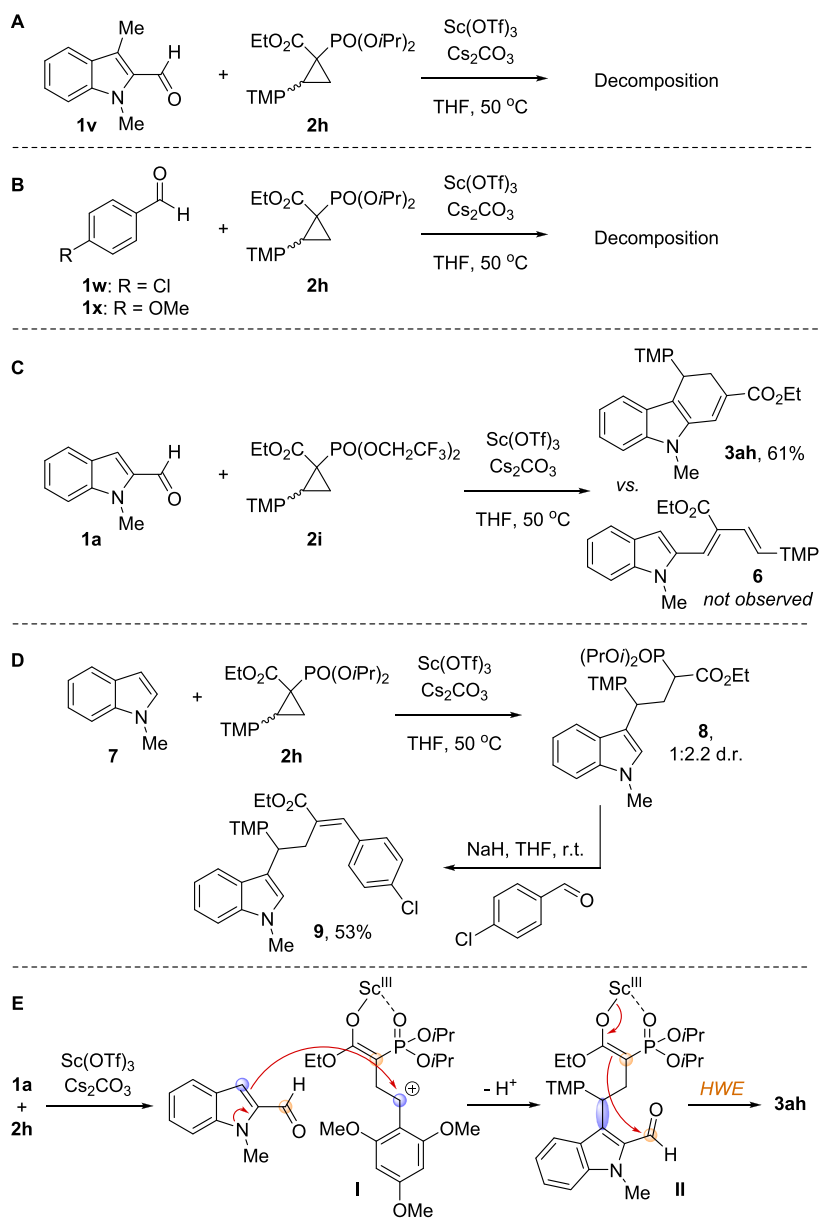

observed, most likely due to steric hindrance. Similarly, substituted benzaldehydes $\mathbf{1 w}$ and $\mathbf{1 x}$ (Scheme 5B) did not afford styrene derivatives, demonstrating that the intermolecular HWE step does not take place under these conditions. In both cases, decomposition was observed when the temperature was increased to $100{ }^{\circ} \mathrm{C}$. A key experiment involved the use of cyclopropane $\mathbf{2} \mathbf{i}$ and aldehyde $\mathbf{1}$ (Scheme 5C). Given the $Z$ selectivity of the Still-Gennari olefination, the linear product 6 would be expected if the olefination occurred first. However, dihydrocarbazole $3 \mathrm{ah}$ was obtained in $61 \%$ yield, nearly identical to the analogous reaction with cyclopropane $\mathbf{2 h}$ (68\%), suggesting that the olefination occurs only after the alkylation. Finally, when $N$-methylindole (7, which does not contain an aldehyde moiety) was used, the linear product 8 was obtained (Scheme 5D), providing additional evidence that the reaction is initiated by the alkylation. Because of purification issues, crude 8 was directly reacted with 4chlorobenzaldehyde, affording 9 in $42 \%$ yield over two steps. On the basis of these observations, we postulate the following mechanism: After activation of the DAC $\mathbf{2 h}$, the resulting benzylic cation $\mathbf{I}$ is attacked by the $\mathrm{C} 3$ position of 1a. The formed intermediate II then undergoes intramolecular HWE olefination to give $\mathbf{3 a}$ (Scheme $5 \mathrm{E}$ ).

In conclusion, we report formal $(3+3)$ and $(3+4)$ cycloadditions of 2- or 4-indolecarboxaldehydes and phosphonate-functionalized DACs, affording a wide range of dihydrocarbazoles or cyclohepta $[c d]$ indoles, respectively. A slight modification to the reaction conditions provided selective access to the corresponding fully aromatic carbazoles and cyclohepta $[c d]$ indoles by thermal loss of the electron-rich aryl substituent. The investigation of the mechanism revealed that the alkylation step precedes the olefination, in contrast with our previous findings with vinylcyclopropanes under palladium catalysis. ${ }^{13}$

\section{ASSOCIATED CONTENT}

Supporting Information

The Supporting Information is available free of charge at https://pubs.acs.org/doi/10.1021/acs.orglett.1c02795.

Experimental details and characterization data and ${ }^{1} \mathrm{H}$ and ${ }^{13} \mathrm{C}$ NMR spectra (PDF)

FAIR data, including the primary NMR FID files, for compounds $\mathbf{2 a - i}, \mathbf{3 a a}-\mathbf{a h}, \mathbf{3 b}-\mathbf{u}, \mathbf{4 a}, \mathbf{b}, \mathbf{e}, \mathbf{k}, \mathbf{m}, \mathbf{q}, \mathbf{t}, \mathbf{5 a}, \mathbf{c}, \mathbf{e},-$ $\mathbf{h}, \mathbf{i}, \mathbf{j}, \mathbf{m}$, and $\mathbf{9}$ (ZIP)

\section{AUTHOR INFORMATION}

\section{Corresponding Author}

Eelco Ruijter - Department of Chemistry \& Pharmaceutical Sciences, Amsterdam Institute of Molecular \& Life Sciences (AIMMS), Vrije Universiteit Amsterdam, $1081 \mathrm{HZ}$ Amsterdam, The Netherlands; 이이이.org/0000-00021105-3947; Email: e.ruijter@vu.nl

\section{Authors}

Matteo Faltracco - Department of Chemistry \& Pharmaceutical Sciences, Amsterdam Institute of Molecular \& Life Sciences (AIMMS), Vrije Universiteit Amsterdam, $1081 \mathrm{HZ}$ Amsterdam, The Netherlands

Matteo Damian - Department of Chemistry \& Pharmaceutical Sciences, Amsterdam Institute of Molecular \& Life Sciences (AIMMS), Vrije Universiteit Amsterdam, $1081 \mathrm{HZ}$ Amsterdam, The Netherlands; Present Address: Department of Chemistry and Industrial Chemistry, Universitá di Genova, via Dodecaneso 31, 16146 Genoa, Italy

Complete contact information is available at:

https://pubs.acs.org/10.1021/acs.orglett.1c02795

\section{Notes}

The authors declare no competing financial interest.

\section{ACKNOWLEDGMENTS}

This work was financially supported by The Netherlands Organisation for Scientific Research (NWO). We thank Elwin Janssen for NMR support and Daniël Preschel for HRMS measurements.

\section{REFERENCES}

(1) (a) Schmidt, A. W.; Reddy, K. R.; Knölker, H.-J. Occurrence, Biogenesis, and Synthesis of Biologically Active Carbazole Alkaloids. 
Chem. Rev. 2012, 112, 3193-3328. (b) Bauer, I.; Knölker, H.-J. Synthesis of pyrrole and carbazole alkaloids. Top. Curr. Chem. 2011, 309, 203-253.

(2) (a) Hsiao, S.-H.; Lusvarghi, S.; Huang, Y.-H.; Ambudkar, S. V.; Hsu, S.-C.; Wu, C.-P. The FLT3 inhibitor midostaurin selectively resensitizes $\mathrm{ABCB} 1$-overexpressing multidrug-resistant cancer cells to conventional chemotherapeutic agents. Cancer Lett. 2019, 445, 3444. (b) Thomas, S. M.; Purmal, A.; Pollastri, M.; Mensa-Wilmot, K. Discovery of a Carbazole-Derived Lead Drug for Human African Trypanosomiasis. Sci. Rep. 2016, 6, 32083. (c) Choi, T. A.; Czerwonka, R.; Forke, R.; Jäger, A.; Knöll, J.; Krahl, M. P.; Krause, T.; Reddy, K. R.; Franzblau, S. G.; Knölker, H.-J. Transition metals in organic synthesis - Part 83: Synthesis and Pharmacological Potential of Carbazoles. Med. Chem. Res. 2008, 17, 374-385.

(3) (a) Tian, X.; Song, L.; Hashmi, A. S. K. Synthesis of Carbazoles and Related Heterocycles from Sulfilimines by Intramolecular $\mathrm{C}-\mathrm{H}$ Aminations. Angew. Chem., Int. Ed. 2020, 59, 12342-12346. (b) Raji Reddy, C.; Subbarao, M.; Sathish, P.; Kolgave, D. H.; Donthiri, R. R. One-Pot Assembly of 3-Hydroxycarbazoles via Uninterrupted Propargylation/Hydroxylative Benzannulation Reactions. Org. Lett. 2020, 22, 689-693. (c) Chen, S.; Li, Y.; Ni, P.; Huang, H.; Deng, G. J. Indole-to-Carbazole Strategy for the Synthesis of Substituted Carbazoles under Metal-Free Conditions. Org. Lett. 2016, 18, 53845387. (d) Guo, T.; Han, L.; Wang, T.; Lei, L.; Zhang, J.; Xu, D. Copper-Catalyzed Three-Component Formal $[3+1+2]$ Benzannulation for Carbazole and Indole Synthesis. J. Org. Chem. 2020, 85, 9117-9128. (e) Kundu, S.; Banerjee, A.; Maji, M. S. Brønsted Acid-Catalyzed Tandem Pinacol-Type Rearrangement for the Synthesis of $\alpha$-(3-Indolyl) Ketones by Using $\alpha$-Hydroxy Aldehydes. J. Org. Chem. 2019, 84, 16003-16012. (f) Faltracco, M.; Ortega-Rosales, S.; Janssen, E.; Cioc, R. C.; Vande Velde, C. M. L.; Ruijter, E. Synthesis of Carbazoles by a Diverted Bischler-Napieralski Cascade Reaction. Org. Lett. 2021, 23, 3100-3104.

(4) For reviews, see: (a) Grover, H. K.; Emmett, M. R.; Kerr, M. A. Carbocycles from donor-acceptor cyclopropanes. Org. Biomol. Chem. 2015, 13, 655-671. (b) Cavitt, M. A.; Phun, L. H.; France, S. Intramolecular donor-acceptor cyclopropane ring-opening cyclizations. Chem. Soc. Rev. 2014, 43, 804-818. (c) Schneider, T. F.; Kaschel, J.; Werz, D. B. A New Golden Age for Donor-Acceptor Cyclopropanes. Angew. Chem., Int. Ed. 2014, 53, 5504-5523.

(5) (a) Wei, F.; Ren, C.-L.; Wang, D.; Liu, L. Highly Enantioselective $[3+2]$ Cycloaddition of Vinylcyclopropane with Nitroalkenes Catalyzed by Palladium(0) with a Chiral Bis(tert-amine) Ligand. Chem. - Eur. J. 2015, 21, 2335-2338. (b) Ding, W. P.; Zhang, G.-P.; Jiang, Y. J.; Du, J.; Liu, X. Y.; Chen, D.; Ding, C. H.; Deng, Q. H.; Hou, X. L. Electron-Deficient Alkynes as Dipolarophile in PdCatalyzed Enantioselective $(3+2)$ Cycloaddition Reaction with Vinyl Cyclopropanes. Org. Lett. 2019, 21, 6805-6810. (c) Huang, X. B.; Li, X. J.; Li, T. T.; Chen, B.; Chu, W. D.; He, L.; Liu, Q. Z. PalladiumCatalyzed Highly Enantioselective Cycloaddition of Vinyl Cyclopropanes with Imines. Org. Lett. 2019, 21, 1713-1716.

(6) (a) Petzold, M.; Jones, P. G.; Werz, D. B. $(3+3)$-Annulation of Carbonyl Ylides with Donor-Acceptor Cyclopropanes: Synergistic Dirhodium(II) and Lewis Acid Catalysis. Angew. Chem., Int. Ed. 2019, 58, 6225-6229. (b) Dhote, P. S.; Ramana, C. V. One-Pot Au[III]-/ Lewis Acid Catalyzed Cycloisomerization of Nitroalkynes and [3+ 3]Cycloaddition with Donor-Acceptor Cyclopropanes. Org. Lett. 2019, 21, 6221-6224.

(7) (a) Xu, H.; Hu, J.-L.; Wang, L.; Liao, S.; Tang, Y. Asymmetric Annulation of Donor-Acceptor Cyclopropanes with Dienes. J. Am. Chem. Soc. 2015, 137, 8006-8009. (b) Augustin, A. U.; Merz, J. L.; Jones, P. G.; Mlostoń, G.; Werz, D. B. $(4+3)$-Cycloaddition of Donor-Acceptor Cyclopropanes with Thiochalcones: A Diastereoselective Access to Tetrahydrothiepines. Org. Lett. 2019, 21, 94059409.

(8) (a) Ishikura, M.; Yamada, K.; Abe, T. Simple indole alkaloids and those with a nonrearranged monoterpenoid unit. Nat. Prod. Rep. 2010, 27, 1630-1680. (b) Ishikura, M.; Abe, T.; Choshi, T.; Hibino, $\mathrm{S}$. Simple indole alkaloids and those with a non-rearranged monoterpenoid unit. Nat. Prod. Rep. 2013, 30, 694-752. (c) Ishikura, M.; Abe, T.; Choshi, T.; Hibino, S. Simple indole alkaloids and those with a non-rearranged monoterpenoid unit. Nat. Prod. Rep. 2015, 32, $1389-1471$.

(9) (a) Kerr, M. A.; Keddy, R. G. The annulation of 3-alkylindoles with 1,1-cyclopropanediesters. Tetrahedron Lett. 1999, 40, 56715675. (b) Zhang, J.-Q.; Tong, F.; Sun, B.-B.; Fan, W.-T.; Chen, J.-B.; Hu, D.; Wang, X.-W. Pd-Catalyzed Asymmetric Dearomative Cycloaddition for Construction of Optically Active Pyrroloindoline and Cyclopentaindoline Derivatives: Access to $3 a$-Aminopyrroloindolines. J. Org. Chem. 2018, 83, 2882-2891. (c) Laugeois, M.; Ling, J.; Férard, C.; Michelet, V.; Ratovelomanana-Vidal, V.; Vitale, M. R. Palladium(0)-Catalyzed Dearomative [3 + 2] Cycloaddition of 3Nitroindoles with Vinylcyclopropanes: An Entry to Stereodefined 2,3Fused Cyclopentannulated Indoline Derivatives. Org. Lett. 2017, 19, 2266-2269. (d) Xiong, H.; Xu, H.; Liao, S.; Xie, Z.; Tang, Y. CopperCatalyzed Highly Enantioselective Cyclopentannulation of Indoles with Donor-Acceptor Cyclopropanes. J. Am. Chem. Soc. 2013, 135, 7851-7854.

(10) (a) Pritchett, B. P.; Stoltz, B. M. Enantioselective palladiumcatalyzed allylic alkylation reactions in the synthesis of Aspidosperma and structurally related monoterpene indole alkaloids. Nat. Prod. Rep. 2018, 35, 559-574. (b) Saya, J. M.; Ruijter, E.; Orru, R. V. A. Total Synthesis of Aspidosperma and Strychnos Alkaloids through Indole Dearomatization. Chem. - Eur. J. 2019, 25, 8916-8935. (c) De Luca, V.; Salim, V.; Levac, D.; Atsumi, S. M.; Yu, F. Chapter Ten Discovery and Functional Analysis of Monoterpenoid Indole Alkaloid Pathways in Plants. Methods Enzymol. 2012, 515, 207-229.

(11) For $(3+3)$ cycloadditions, see: (a) Zhu, Z.-Q.; Yu, L.; Sun, M.; Mei, G.-J.; Shi, F. Regioselective $[3+3]$ Cyclization of 2Indolymethanols with Vinylcyclopropanes via Metal Catalysis. Adv. Synth. Catal. 2018, 360, 3109-3116. (b) Talukdar, R.; Tiwari, D. T.; Saha, A.; Ghorai, M. K. Diastereoselective Synthesis of Functionalized Tetrahydrocarbazoles via a Domino-Ring Opening-Cyclization of Donor-Acceptor Cyclopropanes with Substituted 2-Vinylindoles. Org. Lett. 2014, 16, 3954-3957. (c) Grover, H. K.; Lebold, T. P.; Kerr, M. A. Tandem Cyclopropane Ring-Opening/Conia-ene Reactions of 2Alkynyl Indoles: A [3 +3] Annulative Route to Tetrahydrocarbazoles. Org. Lett. 2011, 13, 220-223. (d) Chen, W.; Zhang, H.-H.; Luo, Y.-C. $\mathrm{Sc}(\mathrm{OTf})_{3}$-Catalyzed [3+3] Annulation of Cyclopropane 1,1-Diesters with $\beta$-(Indol-2-yl)- $\alpha, \beta$-unsaturated Ketones: Synthesis of Polysubstituted Tetrahydrocarbazoles. Synlett 2015, 26, 1687-1692. For (4 + 3) cycloadditions, see: (e) Li, B. Q.; Qiu, Z.-W.; Ma, A.-J.; Peng, J.B.; Feng, N.; Du, J.-Y.; Pan, H.-P.; Zhang, X.-Z.; Xu, X.-T. Diastereoselective Synthesis of Cycloheptannelated Indoles via Lewis-Acid-Catalyzed $(4+3)$-Cyclization of Donor-Acceptor Cyclopropanes. Org. Lett. 2020, 22, 1903-1907.

(12) Wang, J.; Blaszczyk, S. A.; Li, X.; Tang, W. Transition MetalCatalyzed Selective Carbon-Carbon Bond Cleavage of Vinylcyclopropanes in Cycloaddition Reactions. Chem. Rev. 2021, 121, $110-139$.

(13) Faltracco, M.; Vrande, K. N. A.; Dijkstra, M.; Saya, J. M.; Hamlin, T. A.; Ruijter, E. Pd-Catalyzed Cascade to Benzoxepins by Using Vinyl-Substituted Donor-Acceptor Cyclopropanes. Angew. Chem., Int. Ed. 2021, 60, 14410-14414.

(14) Increased electron density has been associated with a higher DAC reactivity: Kreft, A.; Lücht, A.; Grunenberg, J.; Jones, P. G.; Werz, D. B. Kinetic Studies of Donor-Acceptor Cyclopropanes: The Influence of Structural and Electronic Properties on the Reactivity. Angew. Chem., Int. Ed. 2019, 58, 1955-1959.

(15) See, for example: Capon, R. J.; Rooney, F.; Murray, L. M.; Collins, E.; Sim, A. T. R.; Rostas, J. A. P.; Butler, M. S.; Carroll, A. R. Dragmacidins: New Protein Phosphatase Inhibitors from a Southern Australian Deep-Water Marine Sponge, Spongosorites sp. J. Nat. Prod. 1998, 61, 660-662.

(16) Intriguingly, dihydrocarbazoles 3ac, 3af, and 3ag do not undergo this arene elimination. 